\title{
Warfarin: pharmacological profile and drug interactions with antidepressants
}

\author{
Varfarina: perfil farmacológico e interações medicamentosas com antidepressivos
}

\author{
Juliana Souto Teles ${ }^{1}$, Ellen Yukie Fukuda ${ }^{1}$, David Feder ${ }^{2}$
}

\begin{abstract}
Oral anticoagulants are among the drugs with the greatest number of drug interactions. The concomitant use of several medications is a common practice in patients with cardiovascular problems, who often also present with depression; therefore, the probability of an interaction occurring between warfarin and the antidepressants is high, and may result in increased or decreased anticoagulant activity. Since the possible interactions between these two classes of drugs have been poorly explored in literature, with a risk to the patients who use them, we reviewed the pharmacology of warfarin and its possible interactions with antidepressants. Of the antidepressants analyzed, those that showed relevant effects on the interaction with warfarin were, in decreasing order: paroxetine, venlafaxine, fluoxetine, and duloxetine.
\end{abstract}

Keywords: Warfarin/adverse effects; Antidepressive agents; Drug interactions; Anticoagulants

\section{RESUMO}

Os anticoagulantes orais estão entre as drogas com maior número de interações medicamentosas. 0 uso concomitante de vários medicamentos é uma prática comum em pacientes com problemas cardiovasculares, os quais frequentemente também apresentam depressão; assim, a probabilidade de ocorrer alguma interação entre a varfarina e os antidepressivos é bem expressiva, podendo resultar em um aumento ou uma diminuição da atividade anticoagulante. Como as possíveis interações entre essas duas classes de medicamentos se mostraram pouco exploradas na literatura, com risco aos pacientes que fazem uso delas, revisamos a farmacologia da varfarina e suas possíveis interações com antidepressivos. Dos antidepressivos analisados, os que apresentaram efeitos relevantes na interação com a varfarina foram, em ordem decrescente: paroxetina, venlafaxina, fluoxetina e duloxetina.

Descritores: Varfarina/efeitos adversos; Antidepressivos; Interações de medicamentos; Anticoagulantes

\section{INTRODUCTION}

Oral anticoagulants are among the drugs with greatest number of drug-drug interactions. During the period of one year, in a retrospective study on prescriptions of medicines, at least one medication that interacted with warfarin was prescribed for more than $81.6 \%$ patients who already used it. Drugs that interact accentuating their anticoagulant effect, contributing to increased morbidity and mortality, were prescribed more frequently (Figure 1) ${ }^{(1,2)}$. The drugs reported most often are those that contain acetaminophen, thyroid hormones, simvastatin, and ciprofloxacin ${ }^{(2)}$.

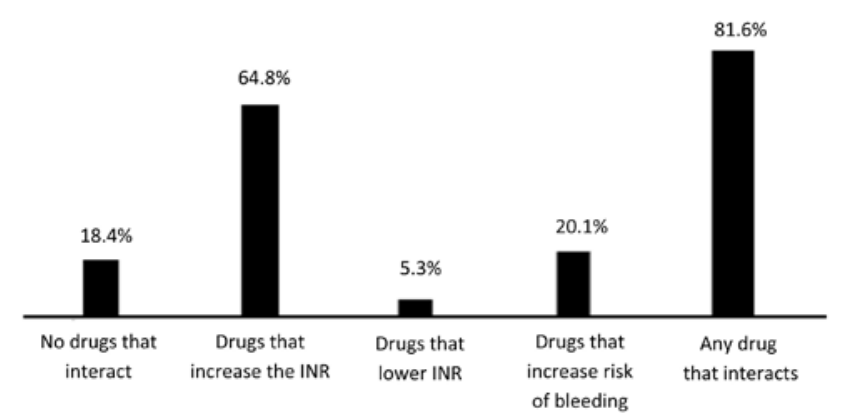

Modified from Wittkowsky AK, Boccuzzi SJ, Wogen J, Wygant G, Patel P, Hauch O. Frequency of concurrent use of warfarin with potentially interacting drugs. Pharmacotherapy. 2004;24(12):1668-74:2)

Figure 1. Percentage of patients in treatment with warfarin who received simultaneous prescriptions of drugs that interact with it

More than one million prescriptions of warfarin are dispensed annually in the United States, making this substance one of the 15 most prescribed drugs, in terms of quantity ${ }^{(3)}$. Additionally, it is expected that its use will increase with the aging of the population, since

\footnotetext{
Undergraduate Course of Medicine, Faculdade de Medicina do ABC - FMABC, Santo Andre (SP), Brazil.

2 Department of Pharmacology, Faculdade de Medicina do ABC - FMABC, Santo Andre (SP), Brazil.

Corresponding author: David Feder - Praça Oswaldo Cruz, 124, conjunto 21 - Paraíso - Zip code: 04006-002 - São Paulo (SP), Brazil - Phone.: (11) 3288-5620 - E-mail: feder2005@gmail.com

Received on: Mar 21, 2011 - Accepted on: Feb 13, 2012

Conflict of interest: None
} 
$75.7 \%$ of its users are elderly ${ }^{(2,3)}$. The same happens with the use of antidepressants, which are among the most prescribed drugs in North America. Their high rate of use is a result not only of the increased number of treatments of depression, but also of the expansion of their use in managing related disorders, particularly anxiety ${ }^{(2-4)}$.

Since the simultaneous use of various medications has become more common, especially among the elderly, and the fact that patients with cardiovascular problems frequently present with depression, the probability of occurrence of some interaction between warfarin and the antidepressive agents is very expressive. Sertraline, paroxetine, and fluoxetine $\operatorname{rank} 8^{\text {th }}$, $9^{\text {th }}$ and $14^{\text {th }}$, respectively, on the list of medications used concomitantly with warfarin ${ }^{(2-4)}$.

In this way, the present study aims to address the pharmacology of warfarin and its possible interactions with various antidepressants.

\section{ORAL ANTICOAGULANTS}

During the 1950s, oral anticoagulants became the mainstay in the prevention of thromboembolic disease and started to be given to millions of patients annually. Warfarin is the prototype of oral anticoagulants, and undoubtedly, the one most often prescribed ${ }^{(5)}$.

\section{WARFARIN}

\section{Mechanism of action}

Warfarin acts as an antagonist of vitamin $\mathrm{K}$, inhibiting reductases involved in the synthesis of hydroquinone from epoxide, particularly epoxide-reductase. The inhibition of the cyclic conversion of vitamin $\mathrm{K}$ induces the hepatic production and secretion of decarboxylated or partially carboxylated proteins that represent 10 to $40 \%$ of normal biological activity ${ }^{(5-8)}$ (Figure 2).

Warfarin has no effects on the activity of fully carboxylated molecules in circulation and at therapeutic doses, diminishing by 30 to $50 \%$ the total quantity of factors II, VII, IX, and X. Therefore, the time necessary for the activity of each plasma factor to reach a new state of dynamic equilibrium after the beginning of therapy, or it adjustment, depends on the individual rate of clearance. Bearing in mind that the half-life of some coagulation factors, such as of factor II, particularly, is long (59 hours), the full antithrombotic effect after the establishment of warfarin therapy is only reached a few days later, despite the fact that the prothrombin time (PT) may increase during its administration due to the rapid reduction of factors with smaller half-life, especially factor VII (6 hours) ${ }^{(6)}$.

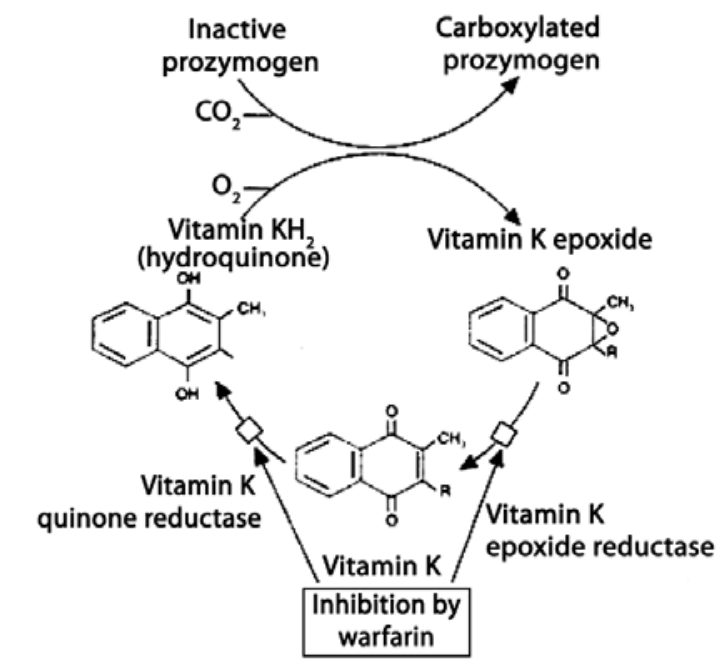

Source: Batlouni M. Anticoalugantes orais. In: Batlouni M, Ramires JAF, editors. Farmacologia e terapêutica cardiovascular 2nd ed. São Paulo: Atheneu; 2004. p. 351-62 ${ }^{77}$.

Figure 2. Cycle of vitamin $\mathrm{K}$ and its inhibition by warfarin

\section{Pharmacokinetics and pharmacodynamics}

\section{Absorption}

When given orally, its absorption is quick and almost complete by the gastrointestinal tract, undergoing reduction in the presence of food ${ }^{(5,6)}$. The maximum concentration in blood is observed within one hour after ingestion. Nevertheless, due to its mechanism of action, this peak does not coincide with maximal pharmacological effect that occurs approximately 48 hours later ${ }^{(5)}$.

\section{Distribution}

Warfarin is strongly bound to plasma albumin ${ }^{(5,6)}$.

\section{Biotransformation and elimination}

Warfarin is a racemic mixture of anticoagulant enantiomers $\mathrm{R}$ and $\mathrm{S}$, in which the latter is five times more potent than the former ${ }^{(9)}$. S-warfarin is transformed into inactive metabolites by isoenzyme CYP2C9, while R-warfarin is transformed by CYP1A2, CYP2C19, and CYP3A4. Its inactive metabolites are excreted in urine and feces. The half-live varies from 25 to 60 hours, with a mean of about 40 hours. The duration of action of warfarin is 2 to 5 days $^{(1-6,10-16)}$.

\section{Indications and contraindications}

The use of warfarin is indicated in the prevention and treatment of venous thromboembolism, in treatment of systemic embolism and cerebrovascular accidents 
(CVA) in patients with valve prostheses and atrial fibrillation, in the primary prevention of myocardial infarct, and in follow-up of patients who presented with myocardial infarct to prevent stroke, insidious infarction, and death ${ }^{(1)}$.

Oral anticoagulants are contraindicated in the presence of blood dyscrasia associated with hemorrhage or thrombocytopenia, cerebral or dissecting aneurisms, confirmed or suspected cerebral hemorrhage, uncontrolled arterial hypertension, ulcerations or active lesions of the gastrointestinal or urinary tracts, recent neurological, ophthalmic and urological surgery, recent trauma, chronic alcoholism, and hepatic insufficiency. Age in and of itself, is not a contraindication, but it requires additional care because of the possibility of associated conditions that predispose towards bleeding. For the same dose of warfarin, the International Normalized Ratio (INR) is usually higher in the elderly, due to potential difficulties of adequate compliance with treatment, risk of accidental falls, CVA, or other comorbidities. During the entire gestation, the use of warfarin should be avoided since it crosses the placental barrier and may cause fetal abnormalities ${ }^{(7)}$.

\section{Adverse effects}

The most important and frequent complications that may occur with the use of warfarin are hemorrhages, which may be related to the value of the INR ( 0.4 to $12 \%$ in retrospective studies). Other adverse reactions include hypersensitivity reactions, cholestatic jaundice, hepatitis, vasculitis, nausea and vomiting, diarrhea, alopecia, etc. Also counted as a complication is the development of new thrombosis or rethrombosis in the presence of treatment, which can occur in cases of venous thromboembolism at a frequency of 3 to $15 \%{ }^{(11)}$.

\section{Interactions}

Interactions may be divided into pharmacokinetic and pharmacodynamic effects ${ }^{(8)}$.

Interactions that modify the pharmacokinetics of warfarin include alterations in absorption, which decreases the anticoagulant effect; in metabolism, whether by inducing isoenzyme $\mathrm{CYP} 2 \mathrm{C} 9$, which increases the clearance of warfarin, reducing anticoagulant activity, or by enzymatic inhibition, which increases the anticoagulant effect and the INR; in transport, since a drug that also binds to plasma albumin dislodges warfarin, causing a rise in its free concentration and in anticoagulant activity ${ }^{(1)}$.

Interactions that modify the pharmacodynamics of warfarin include synergism (affecting hemostasis and decreasing synthesis of coagulation factors, as observed in hepatic diseases), competitive antagonism (vitamin $\mathrm{K}$ ), and alterations of the physiological control loop for vitamin $\mathrm{K}$ (hereditary resistance to oral anticoagulants) ${ }^{(8)}$.

\section{Genetic factors}

In addition to factors such as age, body mass index, vitamin Kingestion, comorbidities, and pharmacological interactions, there are genetic factors that also influence the effect of different dosages of warfarin ${ }^{(12)}$, including hereditary resistance to warfarin, mutations in the polypeptide of factor IX, and polymorphisms of genes CYP2C9 and VKORC1 ${ }^{(13)}$.

\section{PHARMACOLOGICAL INTERACTIONS WITH ANTIDEPRESSANTS}

The tricyclic antidepressants (TCA) are not generally recommended for patients with cardiovascular diseases, since they present with some side effects, such as orthostatic hypotension, sinus tachycardia, and variable prolonging of cardiac conduction times, with the possibility of developing arrhythmias and some of them may also interact with warfarin ${ }^{(14)}$. On the other hand, the monoamine oxidase inhibitors (MAOIs) are reserved for patients that do not respond to energetic attempts of treatment with at least one of the most modern drugs and a classic TCA. There are few indications for the use of MAOIs, and these should be weighed against their potential toxicity and complex interactions with other $\operatorname{drugs}^{(6)}$.

The selective serotonin reuptake inhibitors (SSRIs) are the most prescribed antidepressants and have the highest chances of interacting with warfarin, which can lead to serious clinical consequences ${ }^{(14)}$.

\section{ATYPICAL ANTIDEPRESSANT \\ Duloxetine}

A single case of increased INR resulting from the coadministration of duloxetine and warfarin was reported with the observation of petechiae and purpura after almost two months of treatment, which determined the interruption of warfarin. Surprisingly, the INR continued to rise up to 19 ; intravenous vitamin $\mathrm{K}$ was then administered, causing a momentary drop in the INR, which was only reestablished with the discontinuation of duloxetine and the readministration of warfarin ${ }^{(15)}$.

Two hypotheses were established in the attempt to justify this increase. One relates it to an alteration in the metabolism of warfarin, and the other, with a change in its distribution ${ }^{(15)}$. 
Duloxetine is metabolized by CYP2D6 and CYP1A2, although no clinically significant effect has yet been described on the metabolism of CYP1A2 substrates. Thus, duloxetine may theoretically be involved in the metabolism of warfarin, increasing the risk of hemorrhage ${ }^{(15)}$. It also binds strongly to plasma albumin, and is able, therefore, to dislocate warfarin, possibly resulting in a toxic effect ${ }^{(15)}$.

\section{Selective serotonin reuptake inhibitors}

In theory, SSRIs may increase the risk of bleeding during treatment with warfarin through two mechanisms. They may hinder platelet aggregation by depletion of the levels of platelet serotonin, thus directly increasing the risk of hemorrhage, or they may inhibit the oxidative metabolism of S-warfarin via CYP2C9 $9^{(16,17)}$.

\section{Trazodone}

Among the drugs that interact with warfarin and decrease the INR, trazodone is the most widely prescribed, with a frequency of $2.2 \%$ of the patients who use the anticoagulant, and at least one drug that interacts with it ${ }^{(2)}$.

It also is a drug that binds strongly to plasma albumin and has a short half-life. Trazodone is substrate of isoenzymes CYP2D6 and CYP3A4, while its metabolite, chlorophenyl piperidine, is metabolized by CYP2C19 ${ }^{(18)}$.

Significant interactions between trazodone and warfarin causing a reduction in the PT and INR were reported in four clinical cases, but the mechanism of this interaction is still unknown ${ }^{(18)}$.

\section{Venlafaxine}

This is a substrate and a week inhibitor of CYP2D6. It is not known to influence the metabolism of warfarin, and it binds weakly to plasma albumin $(<30 \%)$. Since the other isoenzymes of the CYP450 system, besides CYP2D6, have not yet been tested, it is possible that an interaction with warfarin may exist, since two cases with an expressive rise in the INR were reported in users of these two medications. In the first case, the patient developed hematuria and gastrointestinal hemorrhage with an INR of 8,873 . In the second case, the INR reached $19^{(14)}$.

\section{Sertraline}

Sertraline binds strongly to plasma albumin and perhaps has some inhibitory effect on CYP2C9, although in vivo interactions still seem relatively small. It also has minimal inhibitory activity on CYP1A2 and CYP3A4, and might be a substrate of this last isoenzyme ${ }^{(14)}$.It has not been tested relative to CYP2C19, but Harvey and Preskorn postulated that any inhibitory effect would be $\operatorname{minimal}^{(19)}$.

Despite the fact that sertraline is the most widely prescribed antidepressant among drugs that interact with warfarin, with a frequency of $5.7 \%$, and that no clinically relevant effect has been verified in the coadministration of these two medicines ${ }^{(2)}$, monitoring the PT in the concomitant use of sertraline and warfarin is strongly recommended, as a significant increase in the PT and in the quantity of free warfarin in plasma have been observed. A study carried out in 12 patients seems to confirm its low risk of interacting with warfarin ${ }^{(14)}$.

\section{Citalopram}

There was a small but statistically significant increase in PT in the combined administration of citalopram and warfarin, although this did not seem to have any clinical relevance. However, theoretically, there is still a risk of interaction, since citalopram is also a substrate of CYP2C19, resulting in possible competitive inhibition $^{(14)}$.

\section{Fluoxetine}

This drug shows a high affinity for plasma albumin and a moderate inhibition of CYP2C19. Its primary metabolite is a moderate inhibitor of CYP3A4, which together with fluoxetine perhaps inhibits CYP2C9. It has been noted that interactions between fluoxetine and warfarin may occur, leading to increased therapeutic response and toxicity. In one case, the patient presented with severe ecchymoses ${ }^{(14)}$. On the other hand, there were three cases in which this administration led to a decrease in $\mathrm{PT}^{(20)}$.

\section{PAROXETINE}

Paroxetine is a weak inhibitor of CYP1A2, CYP2C9, and CYP2D6, and binds strongly to plasma albumin ${ }^{(21,22)}$.

Despite the study conducted by Bannister et al. not having found any significant increase in PT, there was a small, but clinically significant, condition of hemorrhage in 5 of the 27 patients observed after several days of combined paroxetine and warfarin treatment ${ }^{(14)}$.

The bleeding tendency in the coadministration of these drugs is suggested in clinical practice, but is not completely elucidated in this study ${ }^{(22)}$. 


\section{MAOIS}

\section{Tranylcypromine}

This derivative of amphetamine inhibits CYP2C19 and, consequently, an interaction with warfarin is theoretically possible, since there are no studies analyzing its concomitant use ${ }^{(14)}$.

\section{TCAs}

\section{Amitriptyline and nortriptyline}

The effect of TCAs on the function of the CYP450 system is still not clear ${ }^{(23)}$.

The study carried out by Loomis et al. ${ }^{(23)}$ demonstrated that high doses of amitriptyline or nortriptyline inhibit the metabolism of warfarin and consequently, increase its half-life and PT in rats; the reduction of warfarin biotransformation seems to be the result of competitive inhibition; and nortriptyline is a stronger inhibitor of warfarin metabolism than amitriptyline.

Nevertheless, it is possible that this inhibition only occurs with higher doses of amitriptyline or nortriptyline than those used in clinical practice ${ }^{(23)}$. No change in the half-life of warfarin was noted with therapeutic doses of these TCAs $^{(24)}$.

\section{OTHER ANTIDEPRESSANTS}

There are no clinical reports and no scientific studies on the possible interactions between warfarin and the TCAs - bupropion, clomipramine, doxepin and imipramine, the tetracyclic antidepressants maprotiline and mirtazapine, and the noradrenaline reuptake inhibitors amoxapine and desipramine.

\section{CONCLUSION}

The choice of antidepressive agents depends on various factors, including comorbidity, the patient him/herself, and drugs he/she takes.

Of the antidepressants analyzed with prior studies or reports, the only one that showed relevant effects in clinical practice were, in decreasing order, paroxetine, venlafaxine, fluoxetine, and duloxetine.

Both physicians and pharmacists should investigate all medications and supplements for patients receiving treatment with warfarin. Additionally, clinicians who deal with patients under chronic therapy with this medication should restrict the use of drugs and supplements that show interactions not yet established with it for absolutely essential indications, and when appropriate, maintain cautious follow-up.

Considering the high rate of combined prescription of drugs with a high potential for interacting with warfarin, extreme care is needed to avoid adverse reactions. When the patient requires the concomitant use of medicines and several drugs are available to treat the condition, those that do not interact with warfarin should be favored. It is appropriate that the anticoagulant effect be monitored more frequently in patients who use multiple drugs or who have changed any of the drugs of treatment. One retrospective study estimated that one third of the adverse effects related to the use of anticoagulant drugs were avoidable with early diagnosis and changes in treatment.

Keeping well organized notes on the prescribed drugs is also important. In addition, the list of drugs should be revised regularly and updated with the patient, with special attention given to the great assortment of "natural" drugs and products or herbal preparations that the patient uses temporarily. Patients should be given guidance on the importance of taking drugs and supplements.

\section{REFERENCES}

1. Jacobs LG. Warfarin pharmacology, clinical management, and evaluation of hemorrhagic risk for the elderly. Cardiol Clin. 2008;26(2):157-67.

2. Wittkowsky AK, Boccuzzi SJ, Wogen J, Wygant G, Patel P, Hauch 0. Frequency of concurrent use of warfarin with potentially interacting drugs. Pharmacotherapy. 2004;24(12):1668-74.

3. Feldstein AC, Smith DH, Perrin N, Yang X, Simon SR, Krall M, et al. Reducing warfarin medication interactions: an interrupted time series evaluation. Arch Intern Med. 2006;166(9):1009-15.

4. Hardy JL, Sirois A. Reduction of prothrombin and partial thromboplastin times with trazodone. CMAJ. 1986;135(12):1372.

5. Rang HP, Dale MM, Ritter JM, Moore PK. Farmacologia. 5a ed. Rio de Janeiro: Churchill Linvingstone; 2004.

6. Goodman LS, Gilman A. As bases farmacológicas da terapêutica. 11a ed. Rio de Janeiro: Mc Graw Hill; 2006.

7. Batlouni M. Anticoalugantes orais. In: Batlouni M, Ramires JAF, editores. Farmacologia e terapêutica cardiovascular. 2a ed. São Paulo: Atheneu; 2004 p. 351-62.

8. O'Reilly RA. Fármacos utilizados nos distúrbios da coagulação. In: Katzung BG, editor. Farmacologia básica e clínica. 6a ed. Rio de Janeiro: Guanabara Koogan; 1998. p. 86-93.

9. Hirsh J, Dalen J, Anderson DR, Poller L, Bussey H, Ansell J, Deykin D. Oral anticoagulants: mechanism of action, clinical effectiveness, and optimal therapeutic range. Chest. 2001;119(1 Suppl):8S-21S.

10. Sweeney BP, Bromilow J. Liver enzyme induction and inhibition: implications for anaesthesia. Anaesthesia. 2006;61(2):159-77.

11. Santos FC, Maffei FH, Carvalho LR, Tomazini-Santos IA, Gianini M, Sobreira $\mathrm{ML}$, et al. Complicações da terapia anticoagulante com warfarina em pacientes com doença vascular periférica: estudo coorte prospectivo. J Vasc Bras. 2006;5(3):194-202.

12. Singh A. Pharmacogenomics--the potential of genetically guided prescribing Aust Fam Physician. 2007;36(10):820-4.

13. Ansell J, Hirsh J, Poller L, Bussey H, Jacobson A, Hylek E. The pharmacology and management of the vitamin K antagonists: the Seventh ACCP Conference on Antithrombotic and Thrombolytic Therapy. Chest. 2004;126(3 Suppl):204S233S. Erratum in: Chest. 2005;127(1):415-6. Dosage error in article text.

14. Duncan D, Sayal K, McConnell H, Taylor D. Antidepressant interactions with warfarin. Int Clin Psychopharmacol. 1998;13(2):87-94.

15. Monastero R, Camarda R, Camarda C. Potential drug-drug interaction between duloxetine and acenocoumarol in a patient with Alzheimers disease. Clin Ther. 2007;29(12):2706-9. 
16. Kurdyak PA, Juurlink DN, Kopp A, Herrmann N, Mamdani MM. Antidepressants, warfarin, and the risk of hemorrhage. J Clin Psychopharmacol. 2005;25(6): 561-4.

17. Schalekamp T, Klungel $\mathrm{OH}$, Souverein $\mathrm{PC}$, de Boer A. Increased bleeding risk with concurrent use of selective serotonin reuptake inhibitors and coumarins. Arch Intern Med. 2008;168(2):180-5.

18. Jalili M, Dehpour AR. Extremely prolonged INR associated with warfarin in combination with both trazodone and omega-3 fatty acids. Arch Med Res. 2007:38(8):901-4.

19. Harvey AT, Preskorn SH. Cytochrome P450 enzymes: interpretation of their interactions with selective serotonin reuptake inhibitors. Part II. J Clin Pharmacol. 1996;16(5):345-55.
20. Priskorn M, Sidhu JS, Larsen F, Davis JD, Khan AZ, Rolan PE. Investigation of multiple dose cita lopram on the pharmacokinetics and pharmacodynamics of racemic warfarin. Br J Clin Pharmacol. 1997;44(2):199-202.

21. Brøsen K, Naranjo CA. Review of pharmacokinetic and pharmacodynamic interaction studies with citalopram. Eur Neuropsychopharmacol. 2001;11(4):275-83.

22. Bannister SJ, Houser VP, Hulse JD, Kisicki JC, Rasmussen JG. Evaluation of the potential for interactions of paroxetine with diazepam, cimetidine, warfarin, and digoxin. Acta Psychiatr Scand Suppl. 1989;350:102-6.

23. Loomis CW, Racz WJ. Drug interactions of amitriptyline and nortriptyline with warfarin in the rat. Res Commun Chem Pathol Pharmacol. 1980;30(1):41-58.

24. Pond SM, Graham GG, Birkett DJ, Wade DN. Effects of tricyclic antidepressants on drug metabolism. Clin Pharmacol Ther. 1975;18(2):191-9. 